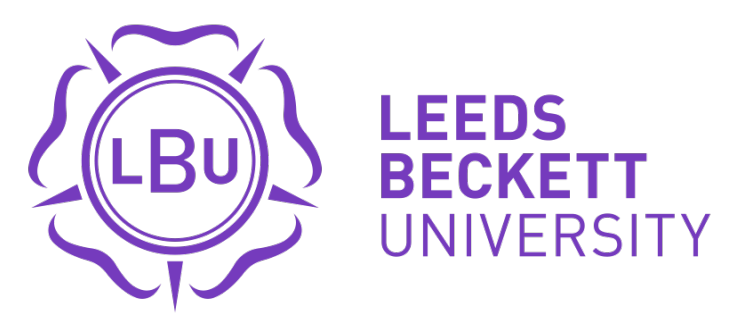

Citation:

Fatorachian, $\mathrm{H}$ and Kazemi, H (2018) A critical investigation of Industry 4.0 in manufacturing: Theoretical operationalization framework. Production Planning and Control, 29 (8). ISSN 0953-7287 DOI: https://doi.org/10.1080/09537287.2018.1424960

Link to Leeds Beckett Repository record:

https://eprints.leedsbeckett.ac.uk/id/eprint/4626/

Document Version:

Article (Accepted Version)

his is an Accepted Manuscript of an article published by Taylor \& Francis in Production Planning and Control on 11 January 2018, available online: http://www.tandfonline.com/10.1080/09537287.2018.1424960

The aim of the Leeds Beckett Repository is to provide open access to our research, as required by funder policies and permitted by publishers and copyright law.

The Leeds Beckett repository holds a wide range of publications, each of which has been checked for copyright and the relevant embargo period has been applied by the Research Services team.

We operate on a standard take-down policy. If you are the author or publisher of an output and you would like it removed from the repository, please contact us and we will investigate on a case-by-case basis.

Each thesis in the repository has been cleared where necessary by the author for third party copyright. If you would like a thesis to be removed from the repository or believe there is an issue with copyright, please contact us on openaccess@leedsbeckett.ac.uk and we will investigate on a case-by-case basis. 


\title{
A critical investigation of Industry 4.0 in manufacturing: Theoretical operationalization framework
}

\author{
Hajar Fatorachian, Hadi Kazemi
}

Leeds Beckett University, Leeds Business School, Rose Bowl, Portland Cres, Leeds LS1 3HB

H.Fatorachian@leedsbeckett.ac.uk (Corresponding author)

Telephone number: 00441138127397

Leeds Beckett University, The School of Built Environment and Engineering, The Northern

Terrace, Queen Square Court, Leeds LS2 8AJ

\section{H.Kazemi@leedsbeckett.ac.uk}

Telephone number: 00441138128921

Hajar is a Senior Lecturer in Leeds Beckett University. She is Course Leader for MSC Management and Global Logistics Course, and Module Leader for International Operations and Global Supply Chain Management Module, and Procurement and Strategic Sourcing Module. Hajar has been involved in various research projects exploring the role of Internet of things (IoT) in Operations and Supply Chain Management. She has, also, been involved in a number of consultancy projects in various Universities, including the Retail Institute at Leeds Beckett University, where she has translated her academic knowledge into professional contexts.

Hadi is a Senior Lecturer in Project Management based in the School of Built environment and Engineering in Leeds Beckett University. His research interests include systems theory in project management, and sustainable project management. He has spent most of his career working as operations and project manager in construction and manufacturing sectors. 


\title{
A critical investigation of Industry 4.0 in manufacturing: Theoretical operationalisation framework
}

\begin{abstract}
Increasing global competition on product quality and production costs, and the need for flexibility in production petition for transformed production processes which enable high level of connectivity and integration between business processes and systems. Much of the conventional computer- integrated efforts and advanced manufacturing technologies are limited in scope and restricted to only some organisational areas. Such limited scope, which stems from limited connectivity and integration between manufacturing and enterprise systems, confines the achievement of full potential of these systems within manufacturing. Industry 4.0, characterised by computing developments, can create a platform for addressing integration challenge through enabling comprehensive connectivity. Hence, this paper, through following deductive research paradigm and using systems theory as the theoretical base, aims to investigate recent academic research and industrial reports in the area of Industry 4.0 and smart manufacturing to provide detailed insights on execution of Industry 4.0, and to propose a theoretical framework for operationalisation of Industry 4.0 in manufacturing.
\end{abstract}

Keywords: Industry 4.0, Internet of Things, Cyber-Physical Systems, manufacturing

\section{Introduction}

In today's manufacturing environment, factors such as agility, efficiency, and responsiveness to changing customer demands, as well as focus on product quality and regulatory compliance determine the survival of manufacturing companies (Brousell, Moad, and Tate 2014). To address the aforementioned challenges and to meet changing customer demands in highly competitive environments, manufacturing strategies and processes need to, not only, be flexible (Anand and Ward 2004) and be able to significantly reduce their operational costs, but also, they need to be smart enough to act intelligently and autonomously (Leitao, Colombo, and Karnouskos 2016; Bechtold et al. 2014; Genovese et al. 2014). This requires high level of digitisation and automation, and 
extensive connectivity in manufacturing environments and throughout organisations, which in turn, calls for seamless integration of production systems/machinery, and enterprise systems (Rashid and Tjahjono 2016).

Although IT is already at the heart of manufacturing, and technological innovations such as sensors, actuators, and computerised automation have been used by manufacturing companies for decades (Naqvi, Farooq, and Johansen 2015), enabling advanced manufacturing, there has been limited benefits offered by them. In other words, the full potential of these technologies has not been realised ( $\mathrm{Da} \mathrm{Xu} 2011)$ as in the current advanced manufacturing environments, IT systems offer limited connectivity and integration between advanced technologies used in manufacturing process, and enterprise/manufacturing systems (Veeramani et al. 1995). At the enterprise level, this is, mainly, due to integration of information systems being limited to a relatively homogenous area, e.g. manufacturing systems with similar interfaces in a manufacturing site (Panetto and Molina 2008). This means that information systems with different interfaces or communication mechanisms will not be able to connect and communicate with each other.

The current trend of integration and lack of interoperability between the information systems (Gruhier, Demoly, and Gomes 2017) makes it difficult for technological innovations and manufacturing/enterprise systems to interconnect and communicate (Panetto and Molina 2008; Chen, Doumeingts, and Vernadat 2008). This integration challenge stems, largely, from the lack of sound communication mechanisms (Vernadat 2002), which prevents interoperability, and consequently, hinders connectivity and integration. Hence, there is a need for a wider operational perspective within manufacturing that enables effective integration and communication between technological innovations and production and enterprise systems, and allows for 
intelligent and autonomous operations (Cheng, Farooq, and Johansen 2015). This necessitates the incorporation of Industry 4.0 perspective and its enabling technologies such as Cyber Physical Systems (CPSs) and Internet of Things (IoT) (Reinhart et al. 2013) into the production process and manufacturing structure (Schlechtendahl et al. 2015). Industry 4.0, fourth industrial revelation brought about by introduction of IoT and CPSs (Kagermann et al. 2013), has emerged as a promising approach to provide extensive connectivity in manufacturing environment (Li, Lai, and Poor 2012).

\section{Industry 4.0 and its relation to CPSs and IoT}

Industry 4.0 involves connection and integration of digital/virtual and real/physical world through CPSs and IoT, where intelligent objects constantly communicate and interact with each other (Oberg and Graham 2016). Industry 4.0 has resulted in a fundamental revolution in manufacturing, characterised by ubiquitous computing, smart networks (cloud computing) and autonomous microcomputers (embedded systems) (Kagermann et al. 2013). This industrial revolution and its enabling technologies are expected to bring about significant efficiency, productivity and performance improvements through enabling enhanced integration and connectivity (Leitao, Colombo, and Karnouskos 2016; LaValle et al. 2011).

CPSs, the cornerstone of Industry 4.0 and the next evolutionary step from embedded systems, are 'intelligent central control units' that operate as 'information processing systems' (Blau 2014, 7). These systems can result in creation of smart factories, where machines, devices and systems are capable of exchanging information, setting course of actions and controlling each other autonomously (Jung et al. 2016). They include distributed communication and computation mechanisms that enable monitoring and controlling of physical entities through application of sensors and actuators (Sheng et al. 2012). CPSs can, also, enable a tight integration of physical and engineering 
systems, and result in enhanced coordination between computational and physical elements (Stojmenovic and Zhang 2015). Moreover, these technological innovations allow for the human-technology integration and enable effective communication between technology and people (Kant 2016).

The pervasive presence and the ubiquitous sensing and communication of smart objects embedded with sensors, actuators, etc. in cyber physical environments, and their inter-connectivity with the Internet has resulted is creation of IoT (Atzori et al. 2010), wherein the Internet acts as the centre of connectivity for smart devices, machinery and systems (Babiceanu and Seker 2016; Thramboulidis 2015; Macaulay, Buckalew, and Chung 2015). IoT can enable high level of automation and integration between intelligent machinery and manufacturing systems, through enabling their connection to each other and to the Internet (Thramboulidis and Christoulakis 2016; Li et al. 2016; Thramboulidis 2015). This technological innovation can offer new business models and collaborative networks that, through enabling enhanced integration, can fundamentally improve the way products are developed, designed and manufactured ( $\mathrm{Li}$ et al. 2016). This can, consequently, provide novel opportunities in terms of efficiency improvements, cost savings and revenue growth (Zhong et al. 2015; Bechtold et al. 2014).

In order to harness the value of IoT and CPSs in manufacturing and production process, there is a need for new business models and new operational structures that allow for high level of integration and connectivity between machinery and manufacturing and enterprise systems ( $\mathrm{Li}$ et al. 2016; Brousell, Moad, and Tate 2014). Hence, this paper aims to investigate Industry 4.0 and its enabling technologies as a new operational approach in manufacturing to explore following research questions;

(1) How does Industry 4.0 address the integration challenge in current advanced manufacturing environments, and how can it enable comprehensive connectivity? 
(2) What are the main enablers of this integration?

(3) How can industry 4.0 be operationalised in manufacturing?

This paper is organised as following; first, smart manufacturing and Industry 4.0 are explored in depth, and drivers and enablers of Industry 4.0, and benefits and challenges of adoption are analysed. This will address the first 2 research questions. Next, having investigated the interconnectivity/interoperability of enablers and their communication mechanisms, a framework for operationalisation of Industry 4.0 perspective in manufacturing is proposed. This, will address the last research question by demonstrating how the interconnectivity of machinery, and manufacturing and enterprise systems can lead to comprehensive integration in manufacturing environment.

\section{Research methodology}

This research attempts to analyse industry 4.0 and smart manufacturing to explore technological innovations enabling extensive integration in manufacturing environments. It, also, aims to propose a framework for operationalisation of Industry 4.0 in manufacturing. The study follows a deductive research approach which begins with identifying a theoretical base for guiding and directing the research (Creswell 2009). Having explored the research topic, and the main enablers and their interconnectivity, the research questions are investigated and conceptualised in the form of a theoretical framework underpinned by systems theory.

Organisations are considered as socio-technical systems consisting of people, technology and machines (Emery and Trist 1960). The awareness of relationships and interactions between these components is very important as it allows for understanding organisations as a whole and integrative entity (Mele, Pels and Polese 2010). This is advocated by systems theory which considers organisations as holistic systems, where 
there is high degree of communication and integration between the factors involved in the value creation process (Grant, Shani, and Krishnan 1994). This theory can help gain awareness of interconnections and interoperability of various elements of the research (Neuman 1997) including key technological innovations enabling Industry 4.0, and can allow for discovering systems' dynamics and constraints to optimise the relationships and interconnectivity between various parts of the systems (Skyttner 2005).

Hence, systems theory can provide the conceptual basis for analysing interconnectivity/interoperability and for addressing integration challenge through identifying potential constraints, and can underpin the relationships and connections in the proposed framework.

\section{Research process}

Reviewing relevant literature and industrial reports around Industry 4.0 and smart manufacturing is the preliminary research step that assisted with identifying the gap in the knowledge (limited integration in current advanced manufacturing environment), and led to formulating research questions. The literature review continued to explore the main drivers and enablers of Industry 4.0 and their capabilities and benefits, and to investigate and address research questions. Subsequently, key factors contributing to smart manufacturing were identified, and main constructs and variables were listed, which led to identifying 6 main technological enablers and 6 category of benefits. The identified enablers are technological innovations that are pervasively present in smart manufacturing environments (as discussed in many industrial reports and verified by academic papers) and their interconnectivity is considered essential for seamless information sharing and integration. The analysis of interconnectivity/interoperability of the key enablers and their communication mechanisms, based on systems theory, allowed researchers to develop theorised relationships between main variables of Industry 4.0. 
This formed the basis from which theoretical framework was constructed. Finally, systems theory was applied to develop theoretical framework and to explain the relationships between key variables.

\section{Industry 4.0 and smart manufacturing}

The concept of focused factories (Skinner 1974) and flexible factories (Upton 1995; Skinner 1996) have evolved to the concept of smart factories where factories are, not only, highly flexible and capable of responding rapidly to environmental changes (Anand and Ward 2004), but also, can autonomously trigger appropriate actions (Jung et al. 2016). This has been made possible by enhanced integration and automation brought about by the revolution of Industry 4.0 and its enabling technologies.

Industry 4.0 includes smart factories which are highly flexible and responsive to accelerating innovation cycles (Oberg and Graham 2016; Blau 2014). In smart manufacturing, solid production processes and concrete structures are substituted by configuration regulations, resulting in creation of Reconfigurable Manufacturing Systems (RMS) (Helo and Hao 2017). These systems, through enhancing flexibility, enable quick and cost-efficient response to changing customer and production requirements (Oberg and Graham 2016; Abele et al. 2007), and lead to improved performance (Dubey et al. 2017).

Industry 4.0, through creation of smart networks and systems, can enable greater connectivity and robustness, and can lead to achievement of high quality standards in manufacturing and engineering (Kagermann et al., 2013). For instance, Industry 4.0 can create a dynamic operational environment where business processes are capable of selforganising and self-optimising, based on criteria such as cost, resource availability and demand requirements (Leitao, Colombo, and Karnouskos 2016). In other words, Industry 4.0 can result in generation of novel business models and new ways of creating value in 
manufacturing ( $\mathrm{Li}$ et al. 2016) through enabling dynamic business and engineering processes, and by creating end-to-end, transparent and flexible manufacturing systems. These capabilities can, consequently, facilitate decision-making, and can enable responsiveness to disruptions and failures, which are considered as major challenges in organisations (Maddern et al. 2015; Hu and Kostamis 2015).

Improved decision making resulting from Industry 4.0 leads to productivity improvements across organisations, and subsequently, to greater competitiveness (Bechtold et al. 2014). This happens through industry 4.0 enabling technologies allowing for enhanced integration and self-optimisation on the production side, and shortened product engineering processes and fast and flexible product development in the engineering side (Schuh et al. 2014).

Finally, Industry 4.0 can lead to establishment of intelligent products and factories. Smart factories, can easily deal with the need for rapid product development and flexible production (Vyatkin et al. 2007), and through smart manufacturing processes, they can create smart products that are uniquely recognisable and know their own history and present status (Zhong et al. 2015). These products can, easily, communicate with each other and with their environment, and can, actively, support the manufacturing as they contain the manufacturing process knowledge and consumer application information (Kagermann et al. 2013).

\section{Enablers of Industry 4.0}

A detailed analysis of the key technological innovations enabling Industry 4.0 and their capabilities in manufacturing is provided below. Theses enablers, significantly, influence and depend on each other. Hence, their synchronized communication is necessary for successful implementation of Industry 4.0 perspective in manufacturing. 


\section{Industrial Internet}

Internet, as the main enabler of smart manufacturing and Industry 4.0. Internet, has enabled the management of distributed systems and technologies like Radio Frequency Identification Devices (RFID) (Brettel et al. 2014; Zhang et al. 2011). The new concept of 'Industrial Internet' emphasises the importance of intelligent machines, advanced data analytics, and people in effective management of business processes (Brousell, Moad, and Tate 2014). The integration of the Industrial Internet and production machinery can lead to generating smart processes and products that are capable of communicating and interacting with the machinery and enterprise systems. Introduction of the new Internet protocol IPv62 in 2012 has ensured availability of addresses to enable global networking of smart objects. This has resulted in creation of Internet of Things, where resources, information, objects and people can be networked via the Internet (Kagermann et al. 2013). Hence, Industrial Internet is considered to be the main enabler of Industry 4.0, that in the realm of manufacturing has resulted in fourth industrial revolution.

\section{Internet of Things (IoT)}

Internet of Things, suggested by Kevin Ashton in 1999, defines a global environment where the internet is the centre of connectivity for all the intelligent devices. IoT has been described as 'a world of pervasive connectivity in which hosts of Internet-enabled physical devices constantly feedback valuable information' to enable improved production process and delivery (Brousell, Moad, and Tate 2014, 3). It is expected that IoT will transform the manufacturing industry over the next few years by enabling enhanced connectivity and integration between processes (Babiceanu and Seker 2016). There is forecasted to be 26 billion connected devices by 2020 , generating global revenues of somewhere between $\$ 300$ billion and an astounding $\$ 8.9$ trillion (Brousell, Moad, and Tate 2014). Hence, business opportunities provided by IoT are expected to be 
enormous (Thramboulidis and Christoulakis 2016). Some of the benefits and opportunities offered by IoT include greater insights and visibility and collaboration across the plant floor as well as greater real-time machine-to-machine (M2M) connectivity.

In IoT enabled environment machines will have self-monitoring capabilities and will be able to communicate their real-time performance on production lines (Brousell, Moad, and Tate 2014). This can, not only, enable intelligent and dynamic manufacturing processes, but also can create smart and self-organised logistics that can foresee and react to unforeseen changes throughout the supply chain. In other words, IoT can create an intelligent network along the value chain, in which connected machines, products and systems can autonomously connect and control each other. Moreover, predictive capabilities in IoT enabled vision, can enable machines to foresee failures and to, autonomously, take quick and corrective actions (Leitao, Colombo, and Karnouskos 2016; Shamsuzzoha et al. 2016; Lopez Research 2014).

\section{Cyber Physical Systems (SPSs)}

Integration and networking of embedded systems with each other and with the Internet has resulted in the merging of the virtual world (cyberspace) and the physical world, generating Cyber-Physical Systems (CPSs). CPSs enable communication between humans, machines and products (Babiceanu and Seker 2016; Einsiedler 2013). Through acquisition and processing data, CPSs can autonomously manage certain tasks and communicate with humans via interfaces (Figure 1) (Kagermann et al. 2013; Brettel et al. 2014). 


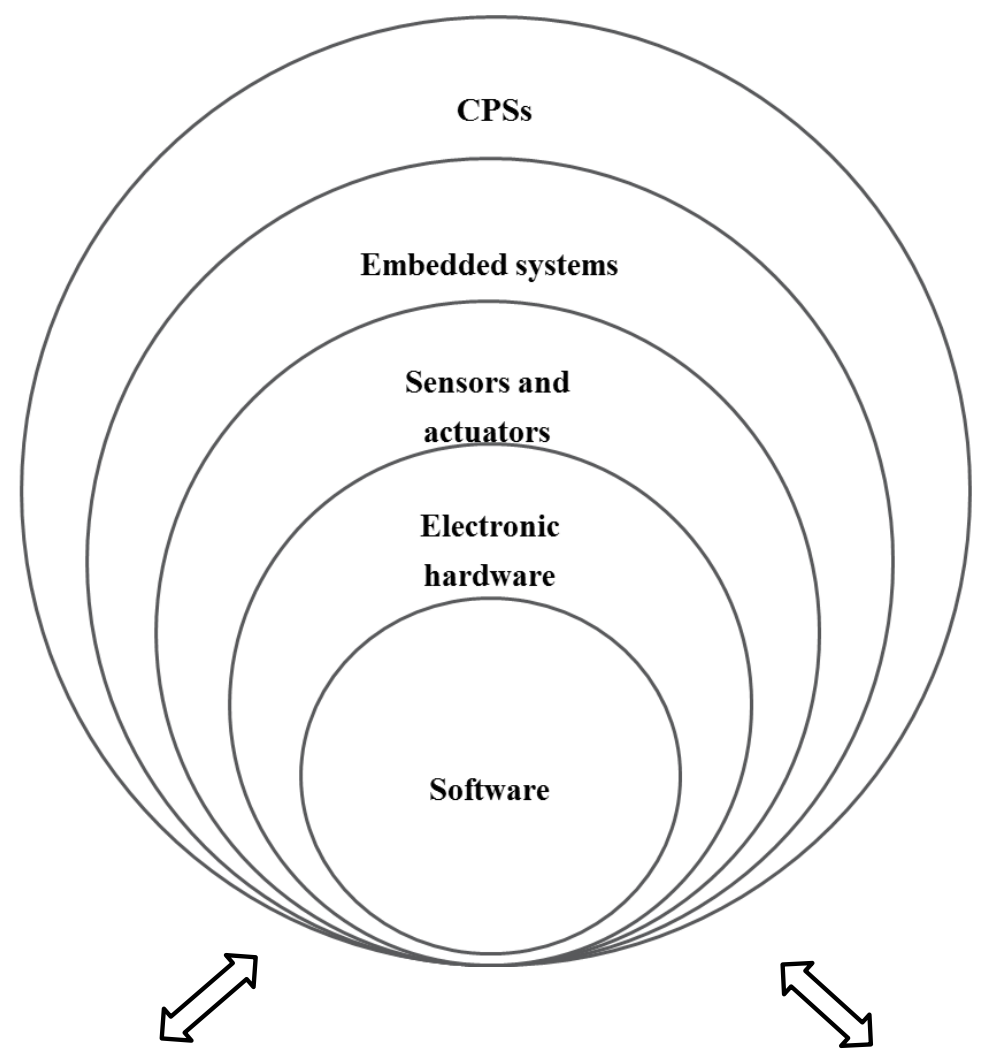

Human-Machine interface

Figure 1. Interaction between humans and machines via Cyber Physical Systems, based on Brettel et al., 2014

Along with Ethernet, Wi-Fi, Bluetooth and cloud systems, which have enabled companies to embed cyber physical intelligence into machines and devices at low cost, innovations such as sensors, actuators and meters have led to intelligent and remote control, monitoring, and sensing (Shamsuzzoha et al. 2016). This, in turn, has resulted in effective and strategic management of product movement throughout the production process and supply chain (Zhong et al. 2015). These technologies, not only, can be used for 'tactical and strategic purposes', but also, they can be applied for identifying constraints and redesigning operational processes (Amini et al. 2007). For example, RFID 
tags, through enabling measurement of operational parameters, can alert workers to product and process failures (Brousell, Moad, and Tate 2014; Modrak and Moskvich 2012), and improve business processes.

CPSs can transform the idea of information sharing and connectivity in manufacturing companies and result in creation of 'mesh architecture' (Vogel-Heuser et al. 2009) in which information clients and servers represent nodes of the mesh (Schlechtendahl et al. 2015). The mesh structure requires communication interfaces for receiving, transforming and exchanging data. This challenge is believed to be addressed by focusing on concepts of 'communication gateway' and 'information server' (Schlechtendahl et al. 2015) which are discussed below.

- Communication gateway

Communication gateway allows detection of available communication interfaces of a production system, and enables connection to production systems through accessing and transmitting data and command interfaces. This gateway act as a server to host and connect all smart objects within a manufacturing plant (Zhang et al. 2011), and is considered as the main enabler that allows production systems to be part of a smart factory (Schlechtendahl et al. 2015).

\section{- CPPS Information Server}

As discussed earlier, CPPSs should allow intelligent production systems to be linked with each other for easy and fast data exchange. However, in order for all machines, devices and systems to be able to connect and exchange information with each other, they need to be aware of other existing CPSs and their communication mechanisms. Therefore, there is a need for an 'overall control centre' to enable extensive connectivity. In other 
words, since different CPPSs have different functionality and communication channel, there is a need for CPPS Information Server which provides information about their communication channels and functionality (Schlechtendahl et al. 2015).

\section{Information network}

One of the main reasons behind creation of networks is to enhance collaboration and to exploit the core competencies of business processes, and, finally, to improve competitiveness by integrating value-added information and resources (Choudhary et al. 2013; Romero and Molina 2011). Similarly, in the context of smart manufacturing, the connectivity and collaboration of devices and machinery is of significant importance. However, based on Macaulay, Buckalew, and Chung (2015), only 4 percent of the devices on the manufacturing floor are 'actually' connected to a network. In order for all devices and machines within a plant to be linked together and effectively communicate with operational and enterprise systems, there is a need for 'standardised IP-centric network' (Lopez Research 2014). These networks can enable visibility and real-time information exchange, not only, within the factory, but also throughout the supply chain, and can lead to horizontal integration of business processes and establishment of smart factories (Brettel et al. 2014). Development of networks can, also, lead to improving competitive advantage and providing 'world class excellence and flexibility' (Choudhary et al. 2013, 1953) as these networks can address the challenge of dynamic and turbulent market environment by capturing valuable business opportunities, and by effective allocation of resources and competencies (Romero and Molina 2011).

\section{Software systems}

The need for effective management and coordination of resources for better production planning in manufacturing industry has resulted in creation of information systems (Koh 
and Saad 2006). However, based on Koh et al. (2008), currently available information systems such as Enterprise Resources Planning (ERP) systems, Advanced Planning and Scheduling (APS), and Supply Chain Management (SCM) do not fully address the collaboration and integration challenges in manufacturing operations. In order to ensure complete connectivity within an enterprise, intelligent software systems should be established to enable regular communication with intelligent devices, machinery and processes (Brousell, Moad, and Tate 2014). For example, management software systems such as Product Lifecycle Management (PLM) which capture all information related to products throughout the value chain, enable real-time communication and realisation of 'single source of truth' across the complete product lifecycle (Schuh et al. 2014; Gecevska et al. 2012). This capability can have a significant impact of product analysis, design and development.

\section{Cloud computing and big data analytics}

Computing power offered by high tech computers has created a great platform for analysing big data generated from IoT. Moreover, cloud systems have enabled high storage capacity and high speed computing, where all data and information can be accessed quickly and independently from any location (Schuh et al. 2014; Hilbert and Lopez 2011). In other words, cloud networks allow for remote communication of products, devices and machines, and enable data generated in multiple sites to be transferred to central data stores for 'subsequent access, aggregation, and analysis' (6). These networks and computing power distributed across them can be very helpful in preprocessing data and preparing data for being uploaded to the main analytical systems such as big data analytics (Brousell, Moad, and Tate 2014). Big data processing tools can provide valuable opportunities in terms of forecasting, proactive maintenance and automation (LaValle et al. 2011). These tools can enable real-time data stream analysis, 
which, in turn, can result in real time problem solving ( $\mathrm{Li}$ et al. 2016) and dramatic improvements in performance (Akter et al. 2016; Wamba et al. 2017).

\section{Drivers and benefits of Industry 4.0 in manufacturing}

As discussed earlier, business and manufacturing environment are becoming more dynamic and complex, and customer requirements are becoming more and more diverse (Genovese et al., 2014). This requires companies to ensure greater flexibility and connectivity in their business processes in order to be able to offer customised products that are superior in quality and competitive in price (Leitao, Colombo, and Karnouskos 2016; Shamsuzzoha et al. 2016).

Industry 4.0 is expected to address the aforementioned organisational challenges by enabling digitisation, automation and integration of production systems (Naqvi, Farooq, and Johansen 2015; Brettel et al. 2014), and through application of computeraided programs and smart systems in manufacturing processes (Macaulay, Buckalew, and Chung 2015). The distributed smart and Internet-based systems can enable 'cybernetic management' which incorporates self-controlling systems to handle high level of complexity in organisations (Brosze 2011). This capability can enhance flexibility and, significantly, improve responsiveness. In other words, companies can gain huge efficiency benefits by development and establishment of smart systems and technologies within their operational processes (Cheng, Pan, and Harrison 2000; Yu et al. 2015).

Many companies have realised the potential benefits of Industry 4.0 enabling technologies, and are making huge investments in advanced technologies and robotics (Chung 2015). Based on PWC (2016) global Industry 4.0 survey, the majority of the companies - around 60\% - expect to see a Return On Investment (ROI) within 2 year or even less for their Industry 4.0 projects, and the rest estimate a ROI of around 5 years. 
Considering the significant benefits and long term impact of advanced technological innovations, the 2-5-year period for ROI seems to be reasonable and realistic.

The main benefits of industry 4.0 and its enabling technologies in manufacturing are discussed below.

\section{Meeting individual customer demands}

Industry 4.0 perspective can enable meeting individual customer requirements through including individual customer-specific criteria in the process of production (Kagermann et al. 2013). Application of IoT and CPSs, as main enablers of Industry 4.0, can create a great platform for automation and integration of machinery and devices (Leitao, Colombo, and Karnouskos 2016), which can facilitate rapid transferring of customer requirements into production processes. Industry 4.0 can, also, enable high level of flexibility and facilitate last-minute changes into the production process (Helo and Hao 2017). This can bring about a variety of benefits including the ability to change outcomes with little change in cost and timeliness (Upton 1995), and improved responsiveness to changing customer demands (Burnes and Towers 2016).

\section{Flexible and agile engineering and manufacturing}

Smart business systems in industry 4.0 enabled environment can enable dynamic and flexible configuration of various business elements, 'such as quality, time, risk, robustness, price and eco-friendliness' (Kagermann et al. 2013, 16). This can result in creation of agile engineering and manufacturing processes which allow for meeting changing customer demands promptly and effectively (Oberg and Graham 2016; Abele et al. 2007). For example, Industry 4.0 and its enabling technologies, through providing end-to-end transparency and visibility about required design elements, allow for on-time verification and quick incorporation of design decisions into engineering and production 
processes. These capabilities can enhance integration and collaboration between different business and manufacturing processes, and can lead to improved responsiveness and decision making (Hu and Kostamis 2015).

\section{Improved information sharing and decision making}

Considering the rapid changes in business environment and customer requirements, making right decisions, especially at very short notice, are becoming very important. Enhanced information exchange in Industry 4.0 is expected to have a huge impact on improving decision making in manufacturing operations (Jung et al. 2016). In Industry 4.0 enabled environment, technological innovations such as IoT and CPSs enable easy access to real-time information and result in effective cooperation between different machinery and manufacturing systems (Lopez Research 2014). The enhanced information sharing and integration can streamline production processes and, significantly, optimise decision making (Yan and Xue 2007). In other words, effective information exchange is considered as a strategic tool to influence the performance of production processes (Guo, Li, and Zhang 2014) as it can significantly influence production quality (Chen and Deng 2015) and product development through enabling high level of integration and improving decision making (Lang et al. 2014).

\section{Improved integration and collaboration}

In Industry 4.0 manufacturing environment, high level of connectivity allows for integration of factory floor operations with enterprise-based systems and decision support tools (Jung et al. 2016). The extensive integration of operations results in improved information sharing and collaboration, and leads to creation of superior competitive advantage (De Toni, Filippini and Forza 1992). The high level of connectivity allows mangers to monitor factory floor operations from any location, and to optimise efficiency 
of devices and machinery by analysing potential process constraints (Guo et al. 2015; Shamsuzzoha et al. 2016). For instance, through mobile-enabled applications, performance data and status updates of production systems can be displayed in tablets, enabling real-time and remote information access and control. This capability can enable transparency, and subsequently, proactive approach towards problem solving (Bechtold et al. 2014).

\section{Improved resource productivity}

Smart devices and intelligent systems can, continuously, optimise manufacturing processes and production systems, especially, in terms of resource and energy consumption (Kagermann et al. 2013). IoT and big data analytics can create cost effective measurement systems and performance management tools, and can provide valuable benefits in the area of resource and energy management (Li et al. 2016; Helo and Hao 2017). These technological innovation, through automation of environmental control tools, facilitate and optimise energy use, as the second largest operational cost in many Industries, and bring about huge cost savings. Moreover, IoT can connect various energy solutions, and can provide economic operational models for the production process (Lopez Research 2014).

\section{Mass customisation}

Industry 4.0 allows for individualisation of manufacturing processes. Individualised production/mass customisation refers to flexible production strategies and business processes that aim to produce personalised mass products (Brecher, Kozielski, and Schapp 2011). Industry 4.0 can enable production of highly customised products at low volume, while still ensuring quality of products and profitability. For example, 3D printing as one of latest technologies in manufacturing, through connecting computers, 
machinery and business processes, has enabled generation of high quality and highly customised products (Zhong et al. 2015). This capability can bring about huge efficiency and productivity improvements in manufacturing.

The summary of the main benefits of industry 4.0 and its enabling technologies in manufacturing are provided in Table 1. 
Table 1. Summary of key benefits of industry 4.0 and its enabling technologies in manufacturing

\begin{tabular}{|c|c|c|c|}
\hline $\begin{array}{l}\text { Industry } 4.0 \\
\text { enabling } \\
\text { technologies }\end{array}$ & Key benefits & Examples of results & References \\
\hline \multirow{6}{*}{$\begin{array}{l}\text { Industrial Internet } \\
\text { Internet of Things } \\
\text { Cyber Physical } \\
\text { Systems } \\
\text { Information } \\
\text { Network } \\
\text { Software Systems } \\
\text { Cloud Computing } \\
\text { Big Data Analytics }\end{array}$} & $\begin{array}{l}\text { Meeting individual } \\
\text { customer demands }\end{array}$ & $\begin{array}{l}\text { - Including individual customer-specific } \\
\text { criteria in the process of production } \\
\text { - Rapid transferring of customer } \\
\text { requirements into production processes } \\
\text { - Enabling high level of flexibility } \\
\text { - Enabling last-minute changes into the } \\
\text { production process }\end{array}$ & $\begin{array}{l}\text { Kagermann et al. } \\
2013 \\
\text { Helo and Hao } 2017 \\
\text { Upton, } 1995\end{array}$ \\
\hline & $\begin{array}{l}\text { Flexible and agile } \\
\text { engineering and } \\
\text { manufacturing }\end{array}$ & $\begin{array}{l}\text { - Dynamic and flexible configuration of } \\
\text { various elements of business processes } \\
\text { - Creation of agile engineering and } \\
\text { manufacturing processes } \\
\text { - On time verification of design decisions } \\
\text { and quick incorporation of decisions into } \\
\text { engineering and production processes } \\
\text { - Improved responsiveness and decision } \\
\text { making }\end{array}$ & $\begin{array}{l}\text { Oberg and Graham } \\
2016 \\
\text { Abele et al. } 2007 \\
\mathrm{Hu} \text { and Kostamis } \\
2015\end{array}$ \\
\hline & $\begin{array}{l}\text { Improved } \\
\text { information sharing } \\
\text { and decision making }\end{array}$ & $\begin{array}{l}\text { - Easy access to real-time information and } \\
\text { effective cooperation between different } \\
\text { machinery and manufacturing systems } \\
\text { - Improved performance and production } \\
\text { quality } \\
\text { - Improved product development }\end{array}$ & $\begin{array}{l}\text { Lopez Research } \\
2014 \\
\text { Chen and Deng } 2015 \\
\text { Lang et al. } 2014\end{array}$ \\
\hline & $\begin{array}{l}\text { Improved } \\
\text { integration } \\
\text { collaboration }\end{array}$ & $\begin{array}{l}\text { - Improved information sharing and } \\
\text { collaboration } \\
\text { - Monitoring operations from any location } \\
\text { - Enabling proactive approach towards } \\
\text { problem solving }\end{array}$ & $\begin{array}{l}\text { Shamsuzzoha et al. } \\
2016 \\
\text { Bechtold et al. } 2014 \\
\text { Lopez Research } \\
2014\end{array}$ \\
\hline & $\begin{array}{l}\text { Improved resource } \\
\text { productivity }\end{array}$ & $\begin{array}{l}\text { - Continuous optimisation of } \\
\text { manufacturing processes and production } \\
\text { systems } \\
\text { - Creating cost effective measurement } \\
\text { systems and performance management } \\
\text { tools } \\
\text { - Automation of environmental control } \\
\text { tools }\end{array}$ & $\begin{array}{l}\text { Kagermann et al. } \\
2013 \\
\text { Lopez Research } \\
2014 \\
\text { Li et al. } 2016 \\
\text { Helo and Hao } 2017\end{array}$ \\
\hline & Mass customisation & $\begin{array}{l}\text { - Individualisation manufacturing } \\
\text { processes } \\
\text { - Production of highly customised } \\
\text { products at low volume } \\
\text { - Generation of high quality and highly } \\
\text { customised products }\end{array}$ & $\begin{array}{l}\text { Brecher, Kozielski, } \\
\text { and Schapp 2011; } \\
\text { Zhong et al. } 2015\end{array}$ \\
\hline
\end{tabular}




\section{Challenges of adoption of Industry 4.0 perspective and potential solutions}

One of the biggest challenges in smart manufacturing is how to capture and make sense of machine-generated data and turn it into valuable information that would facilitate decision making (Zrousell, Moad, and Tate, 2014). In other words, although big data create valuable business opportunities with regards to realisation of the potential of business and creation of competitive advantage, analysing this data can be a big challenge. Moreover, the analysis of data in Industry 4.0 requires different kinds of structures, processes and technologies, which necessitate companies to go through fundamental changes, and embrace all the needed adjustments and adaptations. For example, interpretation of IoT generated data requires companies to establish dedicated analytics units for analysing data, and use relevant analytical technologies such as big data analytics and cloud computing technologies (Macaulay, Buckalew, and Chung 2015). However, the adoption and initial implementation of such technologies can be very costly (Lin and Chen 2012).

The other significant challenge for smart factories is concerned with security issues (Leitao 2016) as IoT is associated with vulnerability to interference and cyberattack (Babiceanu and Seker 2016; Kache and Seuring 2017). In order to address this challenge, safeguards and security procedures such as 'hardware encryption, physical building security and network security for data in transit' should be put in place (Lopez Research 2014, 8).

Within an IoT enabled environment, there might be, also, technical incompatibilities related to IoT standards and interfaces. This is an important issue since IoT data generated in multiple sources needs to be integrated into analytical and decision making systems for further analysis. Addressing this issue can be very challenging, as it requires agreement at both sector and industry level (Brousell, Moad, and Tate 2014). 
Additionally, as technological changes bring about high level of transformation and automation, which causes concerns such as job security and redundancy, it is important to consider socio-cultural context when adopting Industry 4.0 production perspective (Kache and Seuring 2017; Acatech 2012).

In general, it is vital to ensure that the organisational structures and manufacturing infrastructure are ready to grasp new opportunities and values created by Industry 4.0. In other words, both technological and cultural structure should support adoption and implementation of intelligent production systems.

\section{Conceptual framework}

As discussed earlier, in current advanced manufacturing environments there is limited connectivity between technological innovations, machinery and production/enterprise systems. In other words, production systems present in advanced manufacturing are, mainly, cross-linked systems that enable communication of production machinery with similar communication mechanisms.

This paper aims to use systems theory to analyse and address this challenge. Systems theory consider systems as dynamic entities with interdependent and interconnected components (Grant, Shani, and Krishnan 1994). Based on this theory, identifying and establishing communication channels and managing relationships and information flow between systems' components can significantly influence the competitiveness of the systems, as they can enable extensive connectivity and integration throughout the systems, and lead to creation of a whole entity (Mele, Pels and Polese 2010). Hence, the main aim of systems theory is to discover systems' dynamics and constraints to optimise the relationships and interconnectivity between various elements of the systems, and subsequently, to improve systems productivity (Skyttner 2005). This theory argues that, application of technology, can enable components to intelligently 
detect key elements for communication, self-organisation and reconfiguration. In other words, based on this theory, technologies can allow systems to easily search for dynamic and intelligent IT-based systems, and to autonomously connect and communicate with them (Barile and Polese 2010).

To enable extensive connectivity within current advanced manufacturing companies, manufacturing companies need to use a broader scope of advanced and computer integrated technologies (Jonsson 2000; Chung and Swink 2009). This requires application of Industry 4.0 technological innovations such as IoT, CPSs and big data analytics that can enable smart detection and connectivity in production floor through creation of Cyber Physical Systems. These technologies can create great value for manufacturing companies through enabling smart operations and comprehensive integration between technological innovations and manufacturing and enterprise systems (Wamba et al. 2015; Zhong et al. 2015; Li et al. 2016). However, operationalisation of Industry 4.0 perspective and implementation of its enabling technologies require new business models and new operational structures that allow for high level of integration and connectivity (Li et al. 2016; Brousell, Moad, and Tate 2014).

Hence, having investigated the Industry 4.0 and its enabling technologies in the manufacturing, and having discussed the initiatives and drivers of implementation of Industry 4.0 concept, the authors attempt to propose a theoretical framework for operationalisation of Industry 4.0 perspective in manufacturing.

The proposed framework will address the last question of the research - how industry 4.0 can be operationalised in manufacturing? - by demonstrating the main enablers and their communication mechanisms, and the resulting comprehensive integration (Figure 2). 


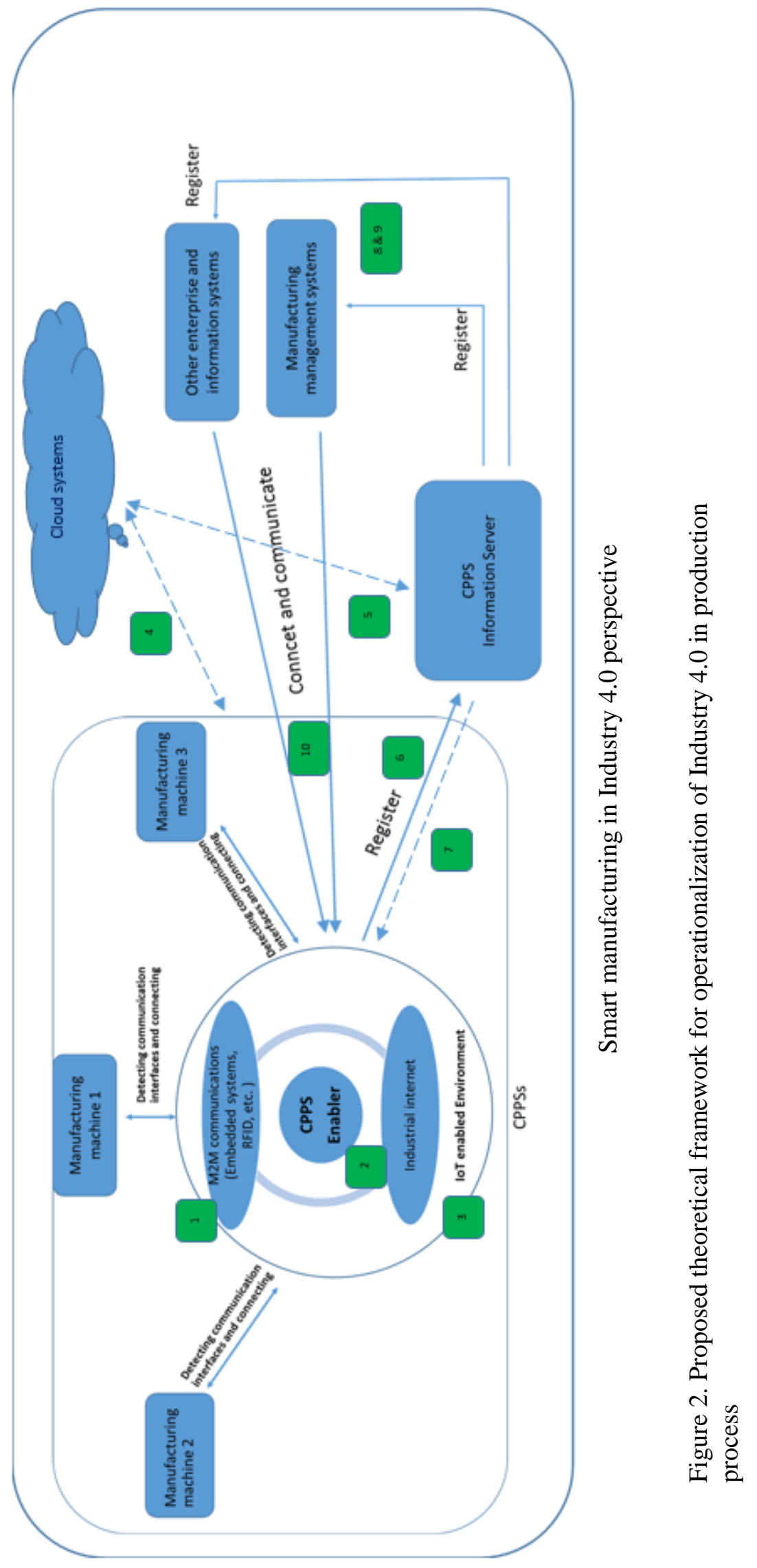


The explanations for different sections of the framework and the interoperability and integration of information systems is provided below.

Technological innovations such as embedded systems, RFID tags and sensors attached to the manufacturing plants and infrastructures such as machinery and devices can enable $\mathrm{M} 2 \mathrm{M}$ communications and result in creation of advanced manufacturing systems (1). However, as different production systems can have different interfaces, and in the same way, different interfaces can have different communication mechanisms and channels, there is a need for a communication gateway called Cyber Physical Production System (CPPS) enabler. CPPS enabler, through connectivity to Industrial Internet, can easily detect, access and transmit available communication interfaces of various production systems (2). This can create an IoT enabled manufacturing environment where CPPSs are connected to the Internet and CPPS enabler (3). An example of CPPS enabler is a 'Cloudplug', that can be used in manufacturing environment to transmit production systems data into the cloud (4) (Atmosudiro and Faller 2014). The cloud networks enable connectivity and remote communication of devices, machinery and systems, and allow for data generated in multiple points to be transferred to central control units (CPPS Information Server) for analysis ad aggregation (5). After the CPPS Enabler creates a connection with the CPPS Information Server, its communication channel and functionality is registered in the CPPS Information Server (6). So, the CPPS Information Server provides information about the communication channel as well as the functionality of connected and available CPPS Enablers. By being aware of communication channels and functionalities, any CPPS can search in the CPPS Information Server for other compatible CPPSs (CPSs with the similar communication channels and functionality), and they can get connected to each other through the same networks (7). Through CPPS Information Server, data links/communication channels can be linked with production 
systems and other enterprise applications (8\&9), such as production management systems to allow for connectivity and communication with production machinery and systems (10), and to enable automatic and smart production processes. The high level of connectivity and Integration, and autonomous interoperability in manufacturing plant can result in creation of smart factories where all manufacturing processes, systems and machinery are connected to each other and to the Internet and cloud systems, and can communicate and control each other effectively, and act autonomously.

This study proposes the application of CPPS enabler and CPPS Information Server as the main step for transforming to smart manufacturing. In other words, to convert advanced production systems to Cyber Physical Production Systems (CPPSs), there is a need for a mechanism that allow for integration of devices, machinery and production systems, and enable access and distribution of their data and command interfaces to the other organisational systems. Until recently, there was no mechanism to automatically discover and connect to other production management systems. However, in Industry 4.0 perspective, IoT can address this challenge by enabling creation of Cyber Physical Production environment where all smart deceives, machinery, and systems can get connected to CPPS enabler through the Internet, and subsequently to central control units (CPPS Information Server) through cloud technologies and big data analytics.

Hence, as demonstrated in the framework, the study proposes CPPS enabler as a solution for Cyber physical level integration, and CPPS Information Server as a solution for enterprise level integration that enables extensive and comprehensive integration between machinery and manufacturing and enterprise systems.

\section{Conclusion}

Today's business world is characterised by intense competitive pressures and growing market demands. Increased demand for customised and innovative products together with 
pressure for improving efficiency and responsiveness call for transformed manufacturing systems/structures which are highly flexible and responsive and capable of dealing with increased complexity. This necessitates high level of integration, connectivity and collaboration between business processes, which, in turn, requires adoption of intelligent technological innovations such as IoT and CPSs. These technological innovations, which enable transparency, real time information sharing and connectivity, have brought about fourth industrial revolution, called 'Industry 4.0'.

Industry 4.0 can offer extensive benefits in manufacturing ranging from flexibility, resource efficiency, and extensive integration and interoperability. It is expected to provide novel opportunities in terms of operational productivity and efficiency improvements, which, in turn, will result in competitiveness and revenue growth for organizations.

This paper explored Industry 4.0 to provide a detailed analysis of smart manufacturing. Having investigated recent academic research and industrial reports in the area of Industry 4.0 and smart manufacturing, it analysed the technological innovations enabling smart manufacturing, and their operational functions and interconnectivity mechanisms. Consequently, a framework for operationalisation of Industry 4.0 in manufacturing was proposed. The proposed framework considers the adoption and application of CPPS enabler and CPPS server as main steps for developing smart manufacturing systems.

\section{Implications of the research}

This study extends existing knowledge by shedding lights on smart manufacturing, and proposing integration mechanisms to allow for extensive connectivity and interoperability in manufacturing environment and to enable smart manufacturing. The paper provides in-depth analysis of key technological innovations and their capabilities 
and functionalities. The awareness of technological enablers of Industry 4.0 can assists with the realisation of their integration and communication techniques, and can facilitate the understanding of operationalisation of Industry 4.0 perspective in manufacturing process.

The proposed framework can create an operational structure for implementation of Industry 4.0 perspective in manufacturing, and can bring valuable insights for operations managers considering engagement in smart manufacturing. The framework includes the main technological innovations that enable smart manufacturing, and demonstrates how CPSs and IoT can address the challenge of limited integration in current manufacturing systems. It demonstrates how proposed integration mechanisms (CPP enabler and CPP Information Server) can allow for Cyber physical level integration and support enterprise level integration, enabling extensive and comprehensive integration between machinery, and manufacturing and enterprise systems.

Hence, the proposed theoretical framework can provide better understanding of smart manufacturing by simple demonstration of the interconnectivity and integration of key Industry 4.0 enabling technologies in manufacturing environment. Using the proposed framework, mangers can scrutinise the readiness of their systems, processes and structures for engagement in Industry 4.0 and smart manufacturing, and can develop tailored implementation plans based on proposed integrative approach and integration solutions in the framework. This, in turn, can facilitate their decision making on adoption and implementation of Industry 4.0 perspective, and can give directions for transforming to smart manufacturing systems by enabling analysis of their current systems and embracing potential required CPSs and technological innovations. 


\section{Limitations and further research directions}

This research is conducted mainly based on deductive approach which applies systems theory as a theoretical basis for analysing potential relationships between main elements and variables of the research topic. In this study, systems theory is expected to explain the major research question (integration challenge) as this theory is, mainly, focused on interaction between main components of the system, and considers organisations as whole and integrative entities. However, future research could focus on application of other theories to analyse the generation of knowledge out of IoT generated data. Moreover, further research can be conducted to study the application and implementation of the proposed framework in practice, and to analyse Cyber Physical integration at supply chain level, including different parties throughout the supply chain. Finally, future research can analyse Return On Investment (ROI) of advanced technological innovations in organisations that are far behand industry 4.0 operational perspective.

\section{References:}

Abele, E., A. Wörn, J. Fleischer, and J. Wieser. 2007. "Mechanical module interfaces for reconfigurable machine tools." Production Engineering 1 (4): 421-428.

Acatech, ed. 2012. Technikzukünfte. Vorausdenken - Erstellen - Bewerten [Future Technology Scenarios. Planning, Production and Evaluation], Deutsche Akademie der Technikwissenschaften (acatech) IMPULSE. Heidelberg: Springer Verlag.

Akter, S., S.F. Wamba, A. Gunasekaran, R. Dubey, and S.J Childe. 2016. "How to improve firm performance using big data analytics capability and business strategy alignment?" International Journal of Production Economics 182: 113-131.

Amini, M., R. F. Otondo, B. D. Janz, and M. G. Pitts. 2007. "Simulation modelling and analysis: a collateral application and exposition of RFID technology." Production and Operations Management 16 (5): 586-598. 
Anand, G., and P. T. Ward. 2004. "Fit, flexibility and performance in manufacturing: coping with dynamic environment." Production and Operations Management 13 (4): 369-385.

Ashton, k. 1999. "That 'Internet of Things' Thing”. RFID Journal. http://www. rfidjournal. com/article/view/4986/

Atmosudiro, A., M. Faller, and A. Verl. 2014. "Seamless integration of production data in the cloud." WT-Online (Werkstattstechnik online), no. 3: 151-155.

Atzori, L., A. Iera, and G. Morabito. 2010. "The internet of things: A survey." Computer networks 54 (15): 2787-2805.

Babiceanu, R. F., and R. Seker. 2016. "Big Data and virtualization for manufacturing cyber-physical systems: A survey of the current status and future outlook." Computers in Industry 81: 128-137.

Barile, S., F. Polese. 2010. "Smart Service Systems and Viable Service Systems: Applying Systems Theory to Service Science.” Journal of Service Science 2 (1/2): 20-39.

Bechtold, J., A. Kern, C. Lauenstein, and L. Bernhofer. 2014. Industry 4.0 - The Capgemini Consulting View. https://www.de.capgemini-consulting.com/resource-fileaccess/resource/pdf/capgemini-consulting-Industry-4.0_0.pdf

Blau, J. 2014. "Revolutionizing Industry the German Way." ResearchTechnology Management 57 (6). URL: https://www.questia.com/library/journal/1P33553044681/revolutionizing-industry-the-german-way.

Brecher C., S. Kozielski, and L. Schapp. 2011. Integrative Production Technology for High-Wage Countries. Heidelberg: Springer.

Brettel, M., N. Friederichsen, M. Keller, and M. Rosenberg. 2014. "How virtualization, decentralization and network building change the manufacturing 
landscape: An Industry 4.0 Perspective." International Journal of Science, Engineering and Technology 8 (1): 37-44.

Brosze, T. 2011. Cybernetic Management versatile production systems. Aachen: Apprimus-Verlag.

Brousell, D. R., J. R. Moad, and P. Tate. 2014. The Next Industrial Revolution: How the Internet of Things and Embedded, Connected, Intelligent Devices will Transform Manufacturing. Frost \& Sullivan, A Manufacturing Leadership White Paper. https://www.allegient.com/wp-content/uploads/FS_Industrial_revolution.pdf

Burnes, B. and N. Towers. 2016. "Consumers, clothing retailers and production planning and control in the smart city." Production Planning \& Control 27 (6): 490-499.

Chen, Y. J., and M. Deng. 2015. "Information Sharing in a Manufacturer-Supplier Relationship: Suppliers' Incentive and Production Efficiency." Production and Operations Management 24 (4): 619-633.

Chen, D., G. Doumeingts. and F. Vernadat. 2008. "Architectures for enterprise integration and interoperability: Past, present and future." Computers in industry 59 (7): 647-659.

Cheng, Y., S. Farooq, and J. Johansen. 2015. "International manufacturing network: past, present, and future." International Journal of Operations \& Production Management 35 (3): 392-429.

Cheng, K., P. Y. Pan, and D. K. Harrison. 2000. "The Internet as a tool with application to agile manufacturing: a web-based engineering approach and its implementation issues." International Journal of Production Research 38 (12): 27432759.

Creswell, J. W. 2009. Research design: Qualitative, quantitative, and mixed methods approaches (3rd ed.). Thousand Oaks, CA: Sage Publications. 
Chung, W., and M. Swink. 2009. "Patterns of advanced manufacturing technology utilization and manufacturing capabilities." Production and Operations Management 18 (5): 533-545.

Chung, C. 2015. Industry 4.0: Smart Factories Need Smart Supply Chains, Longitudes. https://longitudes.ups.com/smart-factories-need-smart-supply-chains/

Einsiedler, I. 2013. "Embedded System for Industry 4.0." Productivity Management 18 (1): 26-8.

Da Xu, L. 2011. "Enterprise systems: state-of-the-art and future trends." IEEE Transactions on Industrial Informatics 7 (4): 630-640.

De Toni, A., R. Filippini, and C. Forza. 1992. "Manufacturing strategy in global markets: An operations management model." International Journal of Operation and Production Management 12 (4): 7-18.

Dubey, R., A. Gunasekaran, P. Helo, T. Papadopoulos, S.J Childe, and B.S. Sahay. 2017. "Explaining the impact of reconfigurable manufacturing systems on environmental performance: The role of top management and organizational culture." Journal of Cleaner Production 141: 56-66.

Einsiedler, I. 2013. "Embedded System for Industry 4.0." Productivity Management 18 (1): 26-8.

Emery, F. E., and E. L. Trist. 1960. "Sociotechnical systems". In Management Sciences: Models and techniques, edited by C.W. Churchman \& M. Verhulst, 83-97. Pergamon Press.

Gecevska, V., I. Veza, F. Cus, Z. Anisic, and N. Stefanic. 2012. "Lean PLM Information Technology Strategy for Innovative and Sustainable Business Environment." International Journal of Industrial Engineering and Management 3 (1): 15-23. 
Grant, R. M., R. Shani, R. Krishnan. 1994. “TQM’s Challenge to Management Theory and Practice." Sloan Management Review 35 (2): 25-35.

Guo, L., T. Li, and H. Zhang. 2014. "Strategic information sharing in competing channels." Production and Operations Management 23 (10): 1719-1731.

Guo, Z. X., E. W. T. Ngai, C. Yang, and X. Liang. 2015. “An RFID-based intelligent decision support system architecture for production monitoring and scheduling in a distributed manufacturing environment." International Journal of Production Economics 159: 16-28.

Gruhier, E., F. Demoly, and S. Gomes. 2017. “A spatiotemporal information management framework for product design and assembly process planning reconciliation." Computers in Industry 90: 17-41.

Helo, P. and Y. Hao. 2017. "Cloud manufacturing system for sheet metal processing." Production Planning \& Control 28 (6-8): 524-537.

Hilbert, M., and P. Lopez. 2011. "The World's Technological Capacity to Store, Communicate, and Compute Information." Science 332 (6025): 60-65.

Hu, B., and D. Kostamis. 2015. "Managing supply disruptions when sourcing from reliable and unreliable suppliers." Production and Operations Management 24 (5): 808-820.

Jonsson, P. 2000. "An empirical taxonomy of advanced manufacturing technology." International Journal of Operation and Production Management 20 (12): $1446-1474$.

Jung, K., S. Choi, B. Kulvatunyou, H. Cho, and K. C. Morris. 2016. “A reference activity model for smart factory design and improvement." Production Planning \& Control 28 (2): 108-122. 
Kache, F., S. Seuring. 2017. "Challenges and opportunities of digital information at the intersection of Big Data Analytics and supply chain management." International Journal of Operations \& Production Management 37 (1):10-36.

Kagermann, H., J. Helbig, A. Hellinger, and W. Wahlster. 2013. Recommendations for Implementing the Strategic Initiative Industry 4.0: Securing the Future of German Manufacturing Industry. Final Report of the Industry 4.0 Working Group. Forschungsunion.

http://www.acatech.de/fileadmin/user_upload/Baumstruktur_nach_Website/Acatech/roo t/de/Material_fuer_Sonderseiten/Industrie_4.0/Final_report_Industrie_4.0_accessible.p df

Kant, V. 2016. "Cyber-physical systems as sociotechnical systems: a view towards human-technology interaction.” Cyber-Physical Systems 2 (1-4): 75-109.

Genovese, A., S. C. L. Koh, N. Kumar, and P.K. Tripathi. 2014. "Exploring the challenges in implementing supplier environmental performance measurement models: a case study." Production Planning \& Control 25 (13-14): 1198-1211.

Choudhary, A. K., J. Harding, L. M. Camarinha-Matos, S. C. L. Koh and M. K. Tiwari. 2013. "Knowledge management and supporting tools for collaborative networks." International Journal of Production Research 51 (7): 1953-1957.

Koh, S. C. L., and S. M. Saad. 2006. "Managing uncertainty in ERP-controlled manufacturing environments in SMEs." International Journal of Production Economics 101: 109-127.

Koh, S. C. L., A. Gunasekaran, and D. Rajkumar. 2008. "ERPII: the involvement, benefits and impediments of collaborative information sharing." International Journal of Production Economics 113 (1): 245-268. 
Lang, M., P. Deflorin, H. Dietl, and E. Lucas. 2014. "The impact of complexity on knowledge transfer in manufacturing networks." Production and Operations Management 23 (11): 1886-1898.

LaValle, S., E. Lesser, R. Shockley., M. S. Hopkins, and N. Kruschwitz. 2011. "Big Data, analytics and the path from insights to value", MIT Sloan Management Review, 52 (2): 21-31.

Leitao, P., A. W. Colombo, and S. Karnouskos. 2016. "Industrial automation based on cyber-physical systems technologies: Prototype implementations and challenges." Computers in Industry 81: 11-25.

Li, H., L. Lai, and H. V. Poor. 2012. "Multicast routing for decentralized control of cyber physical systems with an application in smart grid." IEEE Journal on Selected Areas in Communications 30 (6): 1097-1107.

Li, F., A. Nucciarelli, S. Roden, and G. Graham. 2016. "How smart cities transform operations models: a new research agenda for operations management in the digital economy." Production Planning \& Control 27 (6): 514-528.

Lin, A. and N. C. Chen. 2012. "Cloud computing as an innovation: Perception, attitude, and adoption.” International Journal of Information Management 32 (6): 533540.

Lopez Research. 2014. Building Smarter Manufacturing with the Internet of Things (IoT). Part 2 of 'The IoT Series'. Lopez Research, white paper. http://cdn.iotwf.com/resources/6/iot_in_manufacturing_january.pdf

Macaulay, J., L. Buckalew, and G. Chung. 2015. Internet of things in logistics; A collaborative report by DHL and Cisco. DHL Trend Research and Cisco Consulting Services, DHL Customer Solutions \& Innovation. 
http://www.dpdhl.com/content/dam/dpdhl/presse/pdf/2015/DHLTrendReport_Internet_ of_things.pdf

Maddern, H., P. A. Smart, R. S. Maull, and S. Childe. 2014. "End-to-end process management: implications for theory and practice." Production Planning \& Control 25 (16): 1303-1321.

Mele, C., J. Pels, F. Polese. 2010. "A brief overview of systems theories and their managerial implications." Service Science 2 (1-2): 126-135.

Meyer, G. G., J. C. Wortmann, and N. B Szirbik. 2011. "Production monitoring and control with intelligent products." International Journal of Production Research 49 (5): 1303-1317.

Modrak, V., and V. Moskvich. 2012. "Impacts of RFID implementation on cost structure in networked manufacturing." International Journal of Production Research 50 (14), 3847-3859.

Naqvi, S. T. H., S. Farooq, and J. Johansen. 2015. "Operational performance: The impact of automation and integrated development." Proceedings of the 22nd EurOMA Conference - Operations Management for Sustainable Competitiveness, June 26th - July 1st, Neuchâtel, Switzerland.

Neuman, W. L. 1997. Social Research Methods: Qualitative and quantitative approaches. 3 ed. Needham Heights, Massachusetts: Allyn and Bacon.

Oberg, C. and G. Graham. 2016. "How smart cities will change supply chain management: a technical viewpoint." Production Planning \& Control 27 (6): 529-538.

Panetto, H. and A. Molina. 2008. "Enterprise integration and interoperability in manufacturing systems: Trends and issues." Computers in industry 59 (7): 641-646. 
PWC. 2016. Industry 4.0: Building the digital enterprise Metals key findings. Global Industry 4.0 Survey. https://www.pwc.com/gx/en/metals/pdf/industry-4.0-metalskey-findings.pdf

Rashid, A. and B. Tjahjono. 2016. "Achieving manufacturing excellence through the integration of enterprise systems and simulation." Production Planning \& Control 27 (10): 837-852.

Reinhart, G., P. Engelhardt, F. Geiger, T. Philipp, W. Wahlster, D. Zühlke, and M. Veigt. 2013. Cyber physical production systems: Enhancement of productivity and flexibility by networking of intelligent systems in the factory. wt (Werkstattstechnik online) 103 (2): 84-89.

Romero, D. and A. Molina. 2011. "Collaborative Networked Organisations and Customer Communities: Value Co-creation and Co-innovation in the Networking Era." Production Planning \& Control 22 (5/6): 447-472.

Schlechtendahl, J., M. Keinert, F. Kretschmer, A. Lechler, and A. Verl. 2015. "Making existing production systems Industry 4.0-ready." Production Engineering 9 (1): $143-148$.

Schuh, G., T. Potente, C. Wesch-Potente, A. R. Weber, J. P. Prote. 2014. "Collaboration Mechanisms to increase Productivity in the Context of Industry 4.0." Procedia CIRPI 19: 51-56.

Shamsuzzoha, A., C. Toscano, L. M. Carneiro, V. Kumar, and P. Helo. 2016. "ICT-based solution approach for collaborative delivery of customised products.” Production Planning \& Control 27 (4): 280-298.

Skinner, W. 1974. "The focused factory." Harvard Business Review 52 (3): 113122. 
Skinner, W. 1996. "Manufacturing strategy on the 'S' curve." Production and Operations Management 5 (1): 3-14.

Skyttner, L. 2005. General Systems Theory: Problems, Perspectives, Practice. 2nd ed. World Scientific Publishing: Singapore.

Stojmenovic, I., and F. Zhang. 2015. "Inaugural issue of 'cyber-physical systems'." Journal of production planning and control 1 (1): 1-4.

Thramboulidis, K. 2o15. “A cyber-physical system-based approach for industrial automation systems." Computers in industry 72: 92-102.

Thramboulidis, K. and F. Christoulakis. 2016. "UML4IoT-A UML-based approach to exploit IoT in cyber-physical manufacturing systems." Computers in Industry 82: 259-272.

Upton, D. M. 1995. "Flexibility as process mobility: The management of plant capabilities for quick response manufacturing." Journal of Operations Management 12 (3-4): 205-224.

Veeramani, D., J. J. Bernardo, C. H. Chung, and Y. P. Gupta. 1995. “ComputerIntegrated Manufacturing: A Taxonomy of Integration and Research Issues." Production and Operations Management 4 (4): 360-380.

Vernadat, F. B. 2002. "Enterprise modelling and integration (EMI): Current status and research perspectives." Annual Reviews in Control 26 (1): 15-25.

Vogel-Heuser, B., G. Kegel, K. Bender, and K. Wucherer. 2009. "Global information architecture for industrial automation." ATP Publications. URL: http://ojs.diverlag.de/index.php/atp_edition/article/viewFile/71/787.

Vyatkin, V., Z. Salcic, P. S. Roop, and J. Fitzgerald. 2007. "Now That's Smart!" Industrial Electronics Magazine (IEEE) 1 (4): 17-29. 
Yan, H. S., and C. G. Xue. 2007. "Decision-making in self-reconfiguration of a knowledgeable manufacturing system." International Journal of Production Research 45 (12): $2735-2758$.

Yu, S., A. N. Mishra, A. Gopal, S. Slaughter, and T. Mukhopadhyay. 2015. "EProcurement Infusion and Operational Process Impacts in MRO Procurement: Complementary or Substitutive Effects?" Production and Operations Management 24 (7): 1054-1070.

Wamba, F. S., S. Akter, A. Edwards, G. Chopin, and D. Gnanzou. 2015. "How 'big data' can make big impact: findings from a systematic review and a longitudinal case study.” International Journal of Production Economics 165: 234-246.

Wamba, S.F., A. Gunasekaran, S. Akter, S. J. F. Ren, R. Dubey, and S.J. Childe. 2017. "Big data analytics and firm performance: Effects of dynamic capabilities." Journal of Business Research 70: 356-365.

Zhang, Y., T. Qu, O. K. Ho, and G. Q. Huang. 2011. "Agent-based smart gateway for RFID-enabled real-time wireless manufacturing." International Journal of Production Research 49 (5), 1337-1352.

Zhong, R. Y., C. Xu, C. Chen, and G. Q. Huang. 2015. "Big Data Analytics for Physical Internet-based intelligent manufacturing shop floors." International Journal of Production Research, 1-12. DOI: 10.1080/00207543.2015.1086037. 
Figure 1. Interaction between humans and machine via Cyber Physical systems, based on Brettel et al., 2014

Figure 2. Proposed theoretical framework for operationalization of Industry 4.0 in production process 